\title{
Social conditions of voluntary retirement scheme opted employees among selected large steel manufacturing organizations
}

\author{
Shumaela Naeem Syeda', Rajendra Prasad Das ${ }^{2}$ \\ ${ }^{1}$ Department of Management, Mohammad Ali Jauhar University, Rampur, Uttar Pradesh, India, ${ }^{2} I G N O U 2$, New Delhi, \\ India
}

\section{AbSTRACT}

Purpose: With the advent of NEP, 1991, the Indian economy has transformed due to liberalization, privatization, and globalization. It has shown clear indication to corporate for technology upgradation, cost competitiveness, and workforce rightsizing, with greater emphasis on quality. However, due to the prevailing protectionist labor laws, the corporate has preferred voluntary retirement scheme (VRS) for right sizing their workforce. Nevertheless, the negligence of the managements, during implementation of VRS, has not only led to the financial losses for corporate but also transformed the lives of VRS opted employees in an unconstructive direction. To analyze the impact of VRS over the social conditions of employees, the present study has been conducted. Research Methodology: For the purpose of research, 311 VRS opted employees of large steel manufacturing organizations have been selected. The effect of various independent factors such as family members, friends, relatives, neighbor, social attendance, lifestyle, and financial conditions over the social conditions of VRS opted employees has been studied in detail. Further, for testing hypothesis, the appropriate statistical techniques such as paired $t$-test and independent sample $t$-test have been applied. Findings: It has been found that VRS had negatively impact the social conditions of a section of VRS opted employees and their family members. As, paired t-test has established a significant difference in the social organizational membership of sampled VRS opted employees before and after opting VRS. Implications: Therefore, it has been suggested that management may consider VRS as the last available option, while ensuring the voluntary nature of the scheme. Originality: Until now, no researcher has done, such an in-depth research study in the concern area. The literature on the subject is rarely available. Moreover, the previous researchers have not provided the adequate solutions to the existing research problem.

Keywords: Family members, opted employees, social conditions, voluntary retirement

JEL Classification: \{J26: Retirement, Retirement Policies\}

\section{INTRODUCTION}

The NEP, 1991, has been introduced by the Indian Government to stabilize the Indian macro-economy. The first phase of reforms was directed toward liberalization, privatization, right pricing, and bringing down inflation. In addition to this, the second phase reforms had resulted into enhanced competition among private sectors (Datta,

*Corresponding author:

Shumaela Naeem Syeda, Department of Management, Mohammad Ali Jauhar University, Rampur, Uttar Pradesh, India. E-mail: mbateacher01@gmail.com

Received: 05 August, 2021; Accepted: 15 September, 2021

DOI: $10.18843 / \mathrm{ijcms} / \mathrm{v} 12 \mathrm{i} 3 / 03$ 
2001). These changes in economic scenario demanded a quick restructuring, modernization, and technology up-gradation, along with rapid change in attitude and practices (Sinha and Srivastava, 1995). All the changes adduced above in corporate world, have further resulted into workforce redundancy in business enterprises, which, thereafter, adopted the manpower rationalization strategies to combat this problem. Thus, downsizing or restructuring or rightsizing or redundancy management has emerged as an important cost cutting strategy for most of the organizations (Sinha and Srivastava, 1995). Paradoxically, the knowledgeable and experienced employees, who were the source of competitive advantage and success to their organizations, unexpectedly become a trouble for them (Das and Das, 2009). To overcome the problem of overstaffing and inefficiency, the voluntary retirement scheme (VRS) has been adopted by the public sector enterprises. However, privatization of PSUs has emerged as the end outcome of these schemes (Abraham and Jain, 2020). Consequently, due to protectionist labor laws, the VRS gained prominence in the Indian business sector.

Moreover, intense competition, development in technology, production process, innovation, and new product line along with business restructuring in the prevailing market conditions have further enhanced the implementation of VRS by many Indian business organizations (Kumar and Tripathi, 2015). However, many business organizations have implemented the VRS without proper analysis and planning. As a result, the impact of abandon and hasty implementation of VRS schemes have been observed in the corporate world along with the post-retirement lives of VRS opted employees and their family members. Subsequently, the business organizations had bared the severe cost which has overshadowed the possible gains through implementation of VRS. Moreover, management have faced the embarrassment because of separation of the competent employees (Kumar and Tripathi, 2015). Further, various social, economic, and health issues have been reported in the lives of employees in post-VRS life. The huge reduction in monthly earning, inability to maintain the standard of living along with the financial crisis has severely deteriorated the economic and social conditions of VRS opted employees (Syeda and Das, 2021).

However, the exact influence of VRS over the lives of VRS opted employees at empirical level remained unclear. Further, various dimensions of social lives of VRS opted employees have still remained unfocused. Hence, the present study has been conducted to analyze the overall impact of VRS over the social lives of VRS opted employees. Since, Indian steel industry, one of the largest employers of workforce, has also offered VRS to hundreds of its employees, therefore, the study has been conducted over the $311 \mathrm{VRS}$ opted employees of large steel manufacturing organizations in India.

\section{REVIEW OF LITERATURE}

The VRS, commonly known as VRS, is an early separation scheme for employees who willfully want to retire early in lieu of certain monetary benefits. According to Dey and Ray (2003), voluntary retirement relates to a situation when a worker, for one reason or the other, resigns from his/her job and thereby terminates the employer-employee relationship before the maturity of terms and conditions of employment. Moreover, Narula (2004) defines VRS as the termination of employer-employee relationship voluntarily by worker in exchange of retirement benefits.

Being a voluntary scheme with huge compensation and benefits, it has been considered as a win-win approach for both, management and the VRS opted employees in the corporate world. Eligibility for pension or early retirement incentive offered by employer has also lured the employees to opt for early retirement (Mosca and Barrett, 2014). However, fear of organizational closure has also led many employees to opt VRS (Das and Shukla, 1998). Consequently, a large number of public and private sector employees have opted the VRS being implemented by the respective managements. During 1991-2008, due to disinvestment in 64 public sector undertakings, about 5.94 lakh employees have taken VRS. In Public Sector Banks also, about 1 lakh employees have opted VRS during 2000-2001 (Aggarwal, 2007). In private sector too, many employees have opted VRS. However, these schemes have adversely affected the corporate due to the low morale of their employees. The VRSs have also enhanced the sense of uncertainty among the employees (Kumar and Tripathi, 2015).

In addition, work disparities, work conflicts, excessive work load, and inefficient utilization of self-competency have pushed the employees toward early retirement (Kerstin et al., 2013). Further, health issues, job dissatisfaction, domestic or financial problems, management pressure, and 1 time VRS compensation were the major causes due to which many employees have opted VRS from their respective organizations. Health issues were the major causes of opting VRS by the ex-employees of public sectors. However, job dissatisfaction was the major reason behind opting VRS in private sector (Das and Syeda, 2017). Furthermore, new job, medical rest, money, and to 
start new business had led large number of bank employees to opt for VRS. However, the employees have lost their regular source of income along with the deposited money, after opting VRS (Maheskumar, 2019). Moreover, preretirement health conditions of the employees have also influenced their early retirement decision. The self-rated ill-health, chronic depression, and lack of satisfaction were the major causes of early retirement (Sewdas et al., 2020). As, early retirement improves the individual quality of life, especially in case if ill-health, or job demanding high physical capabilities (Ursina et al., 2021). Therefore, age, health issues, and availability of financial resources have been considered to be the major determinants of early retirement (Topa et al., 2018). Moreover, Aggarwal (2007) has accentuated on the financial attractiveness of the scheme, fear related to job or transfer, poor health, and fear of lowering of the age of retirement to 58 years, as the important reasons behind opting voluntary retirement by the employees. Further, the role of gender (Suri and Poonam, 2003), in the factors influencing the decision of employees regarding VRS, has been emphasized. The better employment opportunity, monotonous job, self or spouse transfer, entrepreneurship lure, children settlement, skill obsolesce, skill upgradation, harassment by superior, self or family health problems, chances of reduction in retirement age, retrenchment threat on the part of government, ambitions to enjoy family life, etc., have led male employees to opt VRS. Whereas the women employees have opted VRS due to self or family health problems, transfer of self or spouse, job redundancy, monotonous job, harassment by superiors, retrenchment threat, better employment opportunities, entrepreneurship lure, children settlement, or to spend time with family. Moreover, the family members and friends have supported their decision for opting VRS (Suri and Poonam, 2003).

However, a large disparity has been observed regarding the impact of VRS over the lives of VRS opted employees. Some studies have reported no negative impact of VRS over the financial (Aggarwal, 2007), health (Mosca and Barrett, 2014), and social status (Aggarwal, 2007) of VRS opted employees. However, few studies have found (Datta, 2001), (Das and Shukla, 1998), and (Kumar and Kumar, 2007) the significant impact of VRS over the lives of employees in post-VRS era.

As per the study of Datta (2001), only a few workers (VRS opted employees) could maintain their standard of living after opting VRS. Moreover, child marriage and others such as debt repayment and house renovation have been found to be the major areas of VRS fund utilization.
Kumar and Kumar (2007) have also found that, after VRS, opted employees got disturbed due to future uncertainties, as they might not have imagined their life without organization. Further, the employees opined that they have lost their social status after opting VRS. Narula (2004) in a study further revealed that many VRS opted employees have felt insecure and tense about their future. Guha (1996) has observed dissatisfaction among employed or self-employed VRS opted workers regarding their present job and status in family as head. Moreover, VRS opted workers were not satisfied with their present status from a psychological and social angle and considered erosion in economic status as the main cause for it.

The life of employees has been severely influenced due to early voluntary retirement. Their own interests have been vanished. They have lost their aims and even the self-confidence. Many have faced high debt due to lack of regular source of income in post-VRS life (Sivasankaran and Vadivel, 2016). Syeda (2008) has also found the downfall in their social status of employees after VRS. Solinge (2007) has found that the inability of the employee to control the retirement as per their desire has adversely affected their health. Further, employees have also experienced a reduction in their perceived health due to the perception of involuntary nature of retirement. However, fear associated with retirement and self-efficacy has resulted into change in the health of retiree. Further, individual unemployment has an adverse effect on the mental health (Mosca and Barrett, 2014). Furthermore, Chatterjee (2007) has revealed that retirees have experienced the roll stagnation in their postretirement life which was so acute, and stressful that one was found unable to accept the situation and experience tremendous insecurity at that point of time in his/her life. These insecurities were mainly due to social, health, or financial perspectives. It has also further deteriorated their health. As there exists a significant relationship between the health factor and the enjoyment factor in the post-VRS life (Muralikrishnan and Suganthalakshmi, 2017). In light of above, Thilaka et al. (2020) have also emphasized on optimum timing in respect to the withdrawal of VRSs, maintaining proper equilibrium regarding the reduction of VRS compensation, and adequate workforce planning for optimal productivity and smooth conduction of business operations.

The above studies have enlightened the impact of VRS over its opted employees. However, a comprehensive approach was absent. Moreover, these researches have not provided the significant details regarding the impact of VRS on the various dimensions of social life of VRS opted employees, especially in respect to the family members, 
neighbor, friends, etc. How VRS has influenced the lives of VRS opted employees? Why VRS has influenced the life of VRS opted employees? Therefore, a study has been conducted on the VRS opted employees of large steel manufacturing organizations to analyze their social conditions in depth.

\section{METHODOLOGY}

A qualitative study has been done to investigate, how the social conditions of VRS opted employees have been influenced in comparison to their life during the employment period in selected large steel manufacturing organizations in India. To fulfill the above purpose, the following objectives were set for the study -

1. To find out the impact of VRS on the social conditions of employees in selected large steel manufacturing organizations in India

2. To analyze how consultation regarding VRS has influenced the behavior of family members toward the VRS opted employee in selected large steel manufacturing organizations in India

3. To determine the behavior, level of respect, and support being offered by the family members to the VRS opted employees in selected large steel manufacturing organizations in India

4. To analyze the impact of VRS over the relationship of employees with friends, relatives, and neighbor, before and after opting VRS in selected large steel manufacturing organizations in India

5. To analyze the social attendance of employees in social gathering before and after opting VRS in selected large steel manufacturing organizations in India

6. To determine the living pattern of VRS opted employees in selected large steel manufacturing organizations in India

7. To study the impact of VRS on the social conditions of his/her family in selected large steel manufacturing organizations in India.

Based on the above objectives, the following hypotheses were formulated for the purpose of study:

Hypothesis 1: There exists no difference in the social conditions of VRS opted employees after opting VRS in selected large steel manufacturing organizations in India.

Hypothesis 2: There exists no difference in the social conditions of VRS opted employees before and after taking VRS in selected large steel manufacturing organizations in India.
For the present study, it is neither feasible nor desirable to collect data from the entire population. Therefore, for the purpose of study, four large steel manufacturing organizations were purposefully selected. Altogether 311 VRS opted employees constitute the sample for the study. Primary data for the study have been collected through a well-designed schedule. For collection of secondary data, researcher visited to various libraries all over India.

Analysis and interpretation of data have been done using the SPSS package. Moreover, descriptive statistics (e.g. means, frequencies, and percentages) were used to state the basic features of the sampled groups. However, for testing hypothesis, the appropriate statistical techniques such as paired $t$-test and independent sample $t$-test have been applied. Moreover, comparative percentage tables have also been developed with the help of frequency tables for analysis and interpretation of findings.

\section{RESULTS AND DISCUSSION}

\section{Demographic Profile}

The majority (87.1\%) of VRS opted employees were male only. Further, $80.1 \%$ VRS opted employees were having the unemployed spouse. At the time of opting VRS, a large section $(60.5 \%)$ of VRS opted employees were below 56 years of age. Moreover, at the time of the survey, majority (54\%) of VRS opted employees of selected large steel manufacturing organizations was found below 61 years of age. In addition, a large section (41.6\%) of VRS opted employees have only passed $\mathrm{X}^{\text {th }}$ or even below than that, before joining their respective organizations.

\section{Social Conditions of VRS Opted Employees under Study after VRS}

The majority (66.5\%) of VRS opted employees of selected large steel manufacturing organizations have consulted with their family members before opting VRS. Guha (1996) as well as Das and Shukla (1998) have also found the same in their respective studies. As a result, the majority (59.4\%) of VRS opted employees have experienced the positive reaction of their family members on their decision of opting VRS. However, a section of respondents $(8.7 \%)$ has also received the negative reaction of their family members on their decision of opting VRS.

After VRS, the level of respect offered by family members has increased in case $37 \%$ of respondents. However, a 
reduction in the level of respect offered by family members has been observed for $6.2 \%$ sampled VRS opted employees. It might be due to their inability to find a suitable job or loss of control over the financial resources. Kumar and Kumar (2007) have also found that, after VRS, more than $15 \%$ VRS opted employees have felt discomfort in their own family. Guha (1996) has also found that about 55.4\% of VRS opted workers have felt that their status in family as head of household has reduced due to decrease in their income.

Further, $43.5 \%$ of respondents have reported more positive behavior of their family members. Conversely, $6.4 \%$ of respondents have observed more negative behavior of their family members in their post-VRS life.

However, $22.6 \%$ of respondents have also lost their control over the financial resources of their families, after opting VRS. It happened due to their unemployment. It might be due to the fact that the most economically dominant member of the family generally controls the financial resources of the family.

After opting VRS, the decisions of the majority (74.9\%) of the sampled respondents have been obeyed by their family members. However, the family members of $21.2 \%$ respondents have obeyed their decisions, sometimes only, after opting VRS. Unfortunately, 3.9\% of respondents have reported that their family members have not at all obeyed their decisions, after their acceptance of VRS.

However, a section $(12 \%)$ of respondents has reported the reduction in the support of their relatives, in their post-VRS life. A section (36\%) of VRS opted employees has also separated from their friends after opting VRS. However, $25.5 \%$ of respondents have observed better relationship with their friend circle, after opting VRS. However, $12 \%$ of respondents have reported worsen relationship between them and their friend circle, in their post-VRS life.

Further, $45.9 \%$ of respondents of selected large steel manufacturing organizations were found restricted to home, in their post-VRS life. In short, due to the age factor, poor health status, unemployment, separation from friends, and society problems, a large section of sampled VRS opted employees has restricted themselves to their homes.

Moreover, $47.3 \%$ of respondents have observed loneliness in their life, after opting VRS. Furthermore, the loneliness in the life of some sampled VRS opted employees of selected organization could have been due to their restriction to home, working children, or death of spouse.
In addition, 19.6\% sampled VRS opted employees have faced less friendly environment in their neighborhood, after opting VRS.

Table 1 illustrates that majority of respondents have occasionally participated in social gatherings before $(80 \%)$ and $(61.6 \%)$ after opting VRS. However, in comparison to that of before, $18.5 \%$ of more respondents have frequently participated in the social gatherings, after opting VRS. It might be due to the availability of sufficient time and desire to fulfill social needs. Further, many of them were experiencing loneliness and restriction to home, in their post-VRS life. As a result, the number of friends has also increased in case of the few respondents, as mentioned in Table 2.

Table 2 illustrates that a large number $(47.7 \%)$ of respondents of selected large steel manufacturing organizations had only a few friends before opting VRS. Moreover, a large section $(42.9 \%)$ of respondents has also reported only a few friends in their post-VRS life. However, as compare to that of before, about $12.28 \%$ of more respondents have reported more than 100 friends in their post-VRS life.

The paired $t$-test has established that there exists a significant difference in the social organizational membership of sampled VRS opted employees of Organization I before and after opting VRS $(\mathrm{t}=-6.603, P<0.001)$. However, no significant difference has been established in case of respondents of Organization II regarding their membership

\begin{tabular}{lcc}
\multicolumn{3}{l}{$\begin{array}{l}\text { Table 1: Participation of respondents in social } \\
\text { gathering before and after voluntary retirement } \\
\text { scheme }\end{array}$} \\
Attendance & Before & After \\
\hline Frequently & $56(18 \%)$ & $113(36.5 \%)$ \\
Occasionally & $248(80 \%)$ & $191(61.6 \%)$ \\
Never & $6(2 \%)$ & $6(1.9 \%)$ \\
Total & 310 & 310 \\
\hline
\end{tabular}

\begin{tabular}{lcc}
\multicolumn{3}{c}{$\begin{array}{c}\text { Table 2: Number of friends of sampled } \\
\text { respondents before and after voluntary } \\
\text { retirement scheme }\end{array}$} \\
No. of friends & Before & After \\
\hline Few & $148(47.74 \%)$ & $133(42.9 \%)$ \\
More than 50 & $139(44.84 \%)$ & $116(37.4 \%)$ \\
More than 100 & $23(7.42 \%)$ & $61(19.7 \%)$ \\
Total & 310 & 310 \\
\hline
\end{tabular}


in social organizations before and after opting VRS $(\mathrm{t}=-1.914, P>0.05)$. In case of sampled VRS opted employees of Organization III, a significant difference has been observed regarding their membership in social organizations before and after opting VRS $(\mathrm{t}=-5.072$, $P<0.001)$. Moreover, the membership of sampled VRS opted employees of Organization IV in social organizations after opting VRS has been found to be significantly different as compare to that of before VRS $(\mathrm{t}=-2.828, P<0.05)$. (Table 3).

As, the majority of respondents of Organizations I, III, and IV were found to be involved in the social activities in their post-VRS life, therefore, a significant difference has been observed in their social organizational membership before and after opting VRS. Further, an independent sample $t$-test has been carried out, to determine whether there exists any difference in the social conditions of VRS opted employees of selected large steel manufacturing organizations after opting VRS.

Through independent sample $t$-test, a significant difference $(P<0.001)$ has been found among the respondents of Organizations I and II; Organizations I and IV; Organizations II and III; as well as Organizations III and IV regarding their membership in social organizations after opting VRS. However, no significant difference $(P>0.05)$ has been found among the respondents of Organizations I and III as well as Organizations II and IV regarding their membership in social organizations after opting VRS. (Table 4)

Table 5 illustrates that majority of the sampled respondents has occasionally visited to their friend's house, before $(85.9 \%)$ and after (63\%) opting VRS. Further, in comparison to that of before, about $22.2 \%$ of more respondents have frequently visited to their friend's house after opting VRS.

\begin{tabular}{lccc}
\hline $\begin{array}{c}\text { Table 3: Membership of respondents in social } \\
\text { organizations before and after voluntary } \\
\text { retirement scheme }\end{array}$ \\
\hline Organization & $\begin{array}{c}\text { Number of } \\
\text { respondents }\end{array}$ & Mean & SD \\
\hline Organization I before & 87 & 1.48 & 1.228 \\
Organization I after & 87 & 2.14 & 1.112 \\
Organization II before & 103 & 0.25 & 0.479 \\
Organization II after & 103 & 0.30 & 0.557 \\
Organization III before & 100 & 0.60 & 0.804 \\
Organization III after & 100 & 0.98 & 1.146 \\
Organization IV before & 21 & 0.00 & 0.000 \\
Organization IV after & 21 & 0.29 & 0.463 \\
\hline
\end{tabular}

However, $0.7 \%$ of more respondents have never visited to their friend's house after opting VRS.

Table 6 illustrates that the majority of respondents has helped others, whenever they found it possible, before and after opting VRS. In addition, $11.1 \%$ of more respondents have helped others whenever they found it possible after opting VRS, as compared to that of before.

However, due to reduction of number of friends and tense relationship with colleagues, relatives, as well as neighbors, a section of sampled VRS opted employees (1.6\%) has never helped others after opting VRS.

Table 7 demonstrates that, majority of respondents were having friendly relationship with their colleagues, before $(51.9 \%)$ and after $(59.7 \%)$ opting VRS. Moreover, in comparison to that of before, $7.8 \%$ of more respondents were having friendly relationship with their colleagues in their post-VRS life. However, $3.6 \%$ of more respondents

\begin{tabular}{|c|c|c|c|}
\hline Organizations & No. of respondents & Mean & SD \\
\hline । & 87 & 2.14 & 1.112 \\
\hline II & 103 & 0.30 & 0.557 \\
\hline III & 100 & 0.98 & 1.146 \\
\hline IV & 21 & 0.29 & 0.463 \\
\hline
\end{tabular}

\begin{tabular}{lcc}
\multicolumn{3}{c}{$\begin{array}{c}\text { Table 5: Visit of sampled respondents to } \\
\text { friend's house before and after voluntary } \\
\text { retirement scheme }\end{array}$} \\
Visit & Before & After \\
\hline Frequently & $33(10.6 \%)$ & $102(32.8 \%)$ \\
Occasionally & $267(85.9 \%)$ & $196(63 \%)$ \\
Never & $11(3.5 \%)$ & $13(4.2 \%)$ \\
Total & 311 & 311 \\
\hline
\end{tabular}

\begin{tabular}{lcc}
\multicolumn{3}{c}{ Table 6: Helping tendency of sampled } \\
\multicolumn{3}{c}{$\begin{array}{c}\text { respondents before and after voluntary } \\
\text { retirement scheme }\end{array}$} \\
Tendency & Before & After \\
\hline Whenever possible & $161(52.4 \%)$ & $195(63.5 \%)$ \\
After thinking & $137(44.6 \%)$ & $98(31.9 \%)$ \\
Never & $9(3 \%)$ & $14(4.6 \%)$ \\
Total & 307 & 307 \\
\hline
\end{tabular}


have also reported the absence of any relationship between them and their colleagues, after opting VRS.

Table 8 illustrates that majority of respondents were having more loving and caring relationship with their relatives, before and after opting VRS. Further, the percentage of respondents having more loving and caring relationship with their relatives has increased by $5.7 \%$, after opting VRS. However, $1 \%$ of more respondents have reported no relationship between them and their relatives, after opting VRS.

Table 9 illustrates that majority of respondents was having more loving and caring relationship with their neighbors, before $(52.4 \%)$ and after (71.7\%) opting VRS. In comparison to that of before, $19.3 \%$ of more respondents were having more loving and caring relationship with their neighbors, after opting VRS. Syeda (2008) has also observed the positive attitude of neighbors in about $94 \%$ of cases, during post-VRS life.

\begin{tabular}{lcc}
\multicolumn{3}{c}{$\begin{array}{c}\text { Table 7: Relationship of respondents with } \\
\text { colleagues before and after voluntary } \\
\text { retirement scheme }\end{array}$} \\
\hline Relationship & Before & After \\
\hline Friendly & $161(51.9 \%)$ & $185(59.7 \%)$ \\
Formal & $126(40.7 \%)$ & $91(29.3 \%)$ \\
None & $23(7.4 \%)$ & $34(11 \%)$ \\
Total & 310 & 310 \\
\hline
\end{tabular}

\begin{tabular}{|c|c|c|}
\hline Relationship & Before & After \\
\hline More loving and caring & 206 (66.5\%) & 224 (72.2\%) \\
\hline None & $5(1.6 \%)$ & $8(2.6 \%)$ \\
\hline Namesake & 99 (31.9\%) & $78(25.2 \%)$ \\
\hline Total & 310 & 310 \\
\hline
\end{tabular}

Table 9: Relationship of respondents with neighbors before and after voluntary retirement scheme

\begin{tabular}{lcc} 
Relationship & Before & After \\
\hline More loving and caring & $163(52.4 \%)$ & $223(71.7 \%)$ \\
Formal & $45(14.5 \%)$ & $16(5.1 \%)$ \\
Namesake & $103(33.1 \%)$ & $72(23.2 \%)$ \\
Total & 311 & 311 \\
\hline
\end{tabular}

A large section (47\%) of respondents has reported improvement in their social status, after opting VRS. However, $8 \%$ of respondents have felt a reduction in their social status, after opting VRS. Kumar and Kumar (2007) have also found that the employees have lost their social status after opting VRS. According to Guha (1996), 4\% of VRS opted workers have reported that their social status has worsened after VRS. According to Solinge (2007), the post-retirement experiences were not only influenced by the factors such as health or organizational limitations which reduced the available number of options to an employee but also by the social environment of the employee.

However, majority ( $84.1 \%)$ of respondents were also found satisfied with their post-VRS social status. Dorfman et al. (1985) also found in the study that satisfaction in regard to retirement depends on the quality of individual relationship and relative support.

\section{Living Pattern of Respondents after VRS}

While analyzing the living pattern of sampled VRS opted employees of selected large steel manufacturing organizations, the following facts have come into light -

Table 10 illustrates that majority (72.5\%) of respondents were involved in social welfare activities in their post-VRS life. Syeda (2008) has also found that a large number of VRS opted employees were engaged in social services. Further, a section of respondents was also found involved in business $(27 \%)$ and political activities (11.1\%) in their post-VRS life. In addition to above, the majority of respondents of selected large steel manufacturing organizations were involved in pooja and meditation $(72.7 \%)$ as well as in family work $(85.4 \%)$ in their post-VRS life. It shows that family work has become the essential part of life for the respondents of all sampled organizations, after opting VRS. It might be due to the busy working schedules of family members.

\section{Impact of VRS on the Social Conditions of Families of VRS opted Employees under Study}

The impact of VRS on the socioeconomic conditions of families of sampled VRS opted employees of selected organizations is discussed below.

Table 11 illustrates the impact of VRS on the family members of sampled VRS opted employees of selected large steel manufacturing organizations, after opting VRS. The interpretation of data in above table is being discussed below. 


\begin{tabular}{lccccc}
\multicolumn{5}{c}{ Table 10: Living pattern of sampled voluntary retirement scheme opted employees } \\
Response & Social welfare & Business & Politics & Pooja and meditation & Family work \\
\hline No & $84(27.5 \%)$ & $224(73 \%)$ & $273(88.9 \%)$ & $84(27.3 \%)$ & $45(14.6 \%)$ \\
Yes & $222(72.5 \%)$ & $83(27 \%)$ & $34(11.1 \%)$ & $224(72.7 \%)$ & $263(85.4 \%)$ \\
Total & 306 & 307 & 307 & 308 & 308 \\
\hline
\end{tabular}

Table 11: Impact of voluntary retirement scheme on the family members of sampled respondents

\begin{tabular}{lccccc} 
Response & Children education & Children marriage & Homelessness & Financial crisis & Loan burden \\
\hline No & $139(48.3 \%)$ & $244(83.6 \%)$ & $234(80.1 \%)$ & $174(59.6 \%)$ & $233(80.3 \%)$ \\
Yes & $149(51.7 \%)$ & $48(16.4 \%)$ & $58(19.9 \%)$ & $118(40.4 \%)$ & $57(19.7 \%)$ \\
Total & 288 & 292 & 292 & 292 & 290 \\
\hline
\end{tabular}

The majority $(51.7 \%)$ of respondents have experienced the influence of VRS in the education of their children. A section (16.4\%) of respondents has also blamed VRS responsible for delay in their children marriage. It might be due to the high demands of dowry and perception regarding VRS as stigma among people. Further 19.9\% of respondents along with their families have experienced homelessness, after VRS. It might be due to the fact that most of them have not utilized their VRS compensation in the construction of home. Even, they failed to plan their home during their service tenure. Moreover, $40.4 \%$ of respondents and their families have experienced the financial crisis, after VRS. It might be due to the inflation and unemployment of respondents. Moreover, the enlarged loan burden after VRS has also resulted in a financial crisis for some of the respondents and their families. As, unemployment and family obligations have increased loan burden for a section of sampled VRS opted employees (19.7\%) and their respective families. About $24.5 \%$ of respondents have also observed the conflict among their family members on financial matters in their post-VRS life.

The social life and respect of family members of a section $(10.9 \%)$ of sampled VRS opted employees have reduced after VRS. In addition, $12.1 \%$ of respondents have reported reduction in the participation of their family members in social gatherings, after opting VRS. A section (14.5\%) of respondents has also reported separation from their children, after opting VRS. In addition, $22.7 \%$ of respondents and their families have faced society's problems, after opting VRS.

\section{Managerial Implications}

VRS has influenced the lives of a section of VRS opted employees. It has been suggested that management may consider VRS as the last available option, while ensuring the voluntary nature of the scheme. Das and Shukla (1998) have also suggested that management of organizations should act carefully now onward while deciding the number of the people, they have to hire through proper workforce planning so that they can avoid this unpleasant event of employment relationship like offering VRS.

Management may organize seminars and workshops on the issues such as better prospects in post-VRS life, opportunities after VRS, financial advices, and making life socially more comfortable and healthy after VRS. Datta (2001) underscored the need for effective counseling and guidance. He suggested that many of VRS opted employees could help in developing the network of suppliers as they have the full knowledge regarding the firm's internal requirements.

Instead of VRS, the managements could use other human resource management methods such as job rotation, phased retirement, transfers, and new market exploration to manage their redundant manpower. This paper has determined the impact areas of VRS opted employees, so the employees can take into account all the options before opting this scheme and employers may take the necessary action to improve the conditions of VRS opted employees.

\section{CONCLUSION}

The study was conducted to determine the social conditions of VRS opted employees. In the study, it has been found that the majority of VRS opted employees have felt an improvement in their social conditions, after opting VRS. However, VRS had negatively impact the social conditions of a section of VRS opted employees and their family 
members. Due to VRS, some persons have felt more negative behavior, disobedience, and reduction in the level of respect offered by their family members. Reductions in the support of relatives, separated from friends, worsen friend circle relationship, restricted to home, loneliness, and less friendly environment in neighborhood have also been felt by a section of VRS opted employees. In short, a section of VRS opted employees has felt a severe reduction in their social status. Further, majority of VRS opted employees had the adverse impact of VRS on the education of their children. Furthermore, the VRS has also resulted in delayed children marriage, homelessness, financial crisis, and loan burden for a large number of VRS opted employees and their respective family members.

Majority of VRS opted employees were involved in social welfare activities, pooja, meditation, and family work in their post-VRS life.

The future researchers may further focus over the social conditions of VRS opted employees in different industrial sectors, such as airline, textile, and IT. Moreover, research attention has also been required regarding the impact of the social, physical health and financial issues of VRS opted employees over their psychological health. The results of such research works will be available to the corporate world for designing better, effective, and supportive VRSs with humane touch.

Although, the present research work has been carried out with due perfection, all limitations cannot be ruled out. Since some of the respondents could not provide complete information in the schedule/questionnaire, so it was not possible to use their response for the purpose of study. Large sections of the population of VRS opted employees of selected organizations were not available either due to their decision to go back to their native places or settled with their grown up children elsewhere. Unfortunately, some of them have passed away. Hence, it was difficult to contact them.

\section{CONFLICTS OF INTERESTS}

This is to bring to your kind consideration that the above Research Paper, "Social Conditions of VRS Opted Employees among Selected Large Steel Manufacturing Organizations" has no Conflict of Interest.

\section{ACKNOWLEDGEMENT}

Acknowledgement is not applicable.

\section{REFERENCES}

Abraham, V., \& Jain, R. (2020). Privatization and the voluntary retirement schemes-the case of BSNL. Economic and Political Weekly, 55(40), 46.

Aggarwal, S. C. (2007). Impact of voluntary retirement scheme on retirees and Indian public sector banks: An empirical exploration. Journal of the Gokhale Institute of Politics and Economics (Artha Vijnana), 18(2), 121-140.

Chatterjee, M. (2007). Identification and impact of post retirement traumas on retired women: Policy resolution for resettlement an Indian case study. Journal of New Delhi Institute of Management, 5(1), 71-89.

Das, R. P., \& Das, S. M. (2009). Rightsizing manpower with a human face. Amity Management Review, 4(1), 58-65.

Das, R. P., \& Shukla, K. K. (1998). Living pattern of VRS opted employees a study. Paradigm, 2(1), 64-71.

Das, R. P., \& Srivastava, S. (2003). Attitude of bankers towards VRS a case study. The Indian Journal of Public Enterprises

Das, R. P., \& Syeda, S. N. (2017). Causes of opting VRS by employees in selected steel manufacturing organizations in India a comparative study. SUMEDHA Journal of Management, 6(1), 69-77.

Datta, R. C. (2001). Life after voluntary retirement: Some plain truths. The Indian Journal of Labour Economics, 44(3), 475-494.

Dey, K., \& Ray, P. (2003). VRS and its effect on productivity and profitability of a firm. The Indian Journals of Industrial Relations, 39(1), 33-57.

Dorfman, L. T., Kohout, F. J., \& Heckert, D. A. (1985). Retirement satisfaction in the rural elderly. Research on Aging, 7(4), 577-599.

Guha, B. P. (1996). Voluntary Retirement- Problem and Prospects of Rehabilitation. New Delhi: Shri Ram Centre for Industrial Relations and Human Resources.

Kerstin, G. R., Astrid, D. W., Marjan, J. W., Jan, F. Y., Allard, J. van der B., \& Goedele, A. G. (2013). All those things together made me retire: Qualitative study on early retirement among Dutch employees. $B M C$ Public Health, 13, 516.

Kumar, S. C., \& Kumar, T. S. (2007). Strategic labor relation and life of workers after acquisition and redundancy: Evidence from two industrial units. The Journal of Indian Management and Strategy, 12(2), 
14-19.

Kumar, S., \& Tripathi, N. (2015). An analysis of impact and implications of voluntary retirement scheme. European Journal of Business and Management, 7(1), 297-302.

Maheskumar, S. (2019). An evaluation of voluntary retirement scheme (VRS) in select public sector bank in Tamil Nadu. Science, Technology and Development, 8(12), 24-43.

Mosca, I., \& Barrett, A. (2014). The impact of voluntary and involuntary retirement on mental health: Evidence from older Irish adults. In: Economic and Social Research Institute and IZA, Discussion Paper No. 8723.

Muralikrishnan, M., \& Suganthalakshmi, T. (2017). A study on perception towards satisfaction after voluntary retirement scheme with special reference to Bharat Sanchar Nigam limited employees, Tamil Nadu. International Journal of Applied Business and Economic Research, 15, 489-494.

Narula, V. (2004). Voluntary Retirement Scheme: Implementation and Effects. Gurgaon, Delhi: Shubhi Publication.

Sewdas, R., Thorsen S. V., Cecile, R. L., Bjorner, J. B., \& Beek A. J. (2020) Determinants of voluntary early retirement for older workers with and without chronic diseases: A Danish prospective study. Scandinavian Journal of Public Health, 48(2), 190-199.

Sinha, B. K., \& Srivastava, R. K. (1995). Rightsizing and Redundancy Management an Experience in Tata Steel. Jamshedpur: TISCO Research Centre.

Sivasankaran, M. S., \& Vadivel, C. (2016). A study on the satisfaction of CRS/VRS individuals and the impact of retirement on them with special reference to OOTY Taluk. IOSR Journal of Business and Management, 18(11), 42-47.
Solinge, H. V. (2007). Health change in retirement a longitudinal study among older workers in the Netherlands. Research on Aging, 29(3), 225-256.

Suri, R. K., \& Poonam. (2003). An analysis of the reasons for voluntary retirement. Delhi Business Review, 4(1), 1-6.

Syeda, R. (2008). Working of Voluntary Retirement Scheme in Public Sector Banks with Special Reference to SBH. Hyderabad: Osmania University.

Syeda, S. N., \& Das, R. P. (2021). VRS and its impact on the social and economic life of VRS opted employees a study. International Journal of Business, Management and Allied Sciences, 8(1), 26-37.

Thilaka, B., Sivasankaran, J., and Udayabaskaran, S. (2020). Optimal time for withdrawl of voluntary retirement scheme with a probability of acceptance of retirement request. Journal of Information Technology and Digital World, 2(4), 201-206.

Topa, G., Depolo, M., \& Alcover, C. M. (2018). Early retirement: A meta-analysis of its antecedent and subsequent correlates. Frontiers in Psychology, 8, 2157.

Ursina, K.; Markus, M. G., \& Christian, S. (2021). Early retirement as a privilege for the rich? A comparative analysis of Germany and Switzerland. Advances in Life Course Research, 48(3), 100392. 